\title{
Knowledge and Attitude of Students on Antimicrobial Resistance at Debre Markos University, Ethiopia
}

\author{
Desalegne Amare Zelellw ${ }^{1}$, Habtamu Mellie Bizuayehu ${ }^{2}$ \\ ${ }^{1}$ Department of Nursing, College of Medicine and Health Sciences, Bahir Dar University, Bahir Dar, Ethiopia \\ ${ }^{2}$ Department of Public Health, College of Health Sciences, Debre Markos University, Debre Markos, Ethiopia
}

\begin{tabular}{l} 
Article Info \\
\hline Article history: \\
Received Sep 10, 2016 \\
Revised Nov 10, 2016 \\
Accepted Nov 22, 2016
\end{tabular}

Keyword:

Antimicrobial

Attitude

Drug resistance

Knowledge

Self-medication

\begin{abstract}
Irrational use of medicines is a key reason for the increase and spread of antimicrobial resistance and it is a global concern. It is a fast mounting universal crisis. The main of this study of this study was to assess knowledge, attitude and practice of university students on antimicrobial resistance at Debre Markos University. Institutional based comparative cross-sectional survey was conducted from June to July with total sample size of 670. Participants were selected using simple random sampling method using random number table. Data clerk double entered the data into Epi data version 3.1 and transferred to SPSS Windows software version 21.0. Those variables that had associations at binary stage with $\mathrm{p}$-value $<0.1$, not collinear and biologically important variables were entered in to multiple logistic regression models. The cut off point for association was p-value $<0.05$. About $14.8 \%$ study participants had adequate knowledge towards drug resistance. Rural residences of the participants were significantly associated with drug resistance as compared to urban residence. Knowledgeable participants were significantly protective to self- medication and drug resistance as compare to those who had inadequate knowledge and participants who had positive attitude were positively associated with self-medication as compare to those who had negative attitude. The overall knowledge of participants regarding to antimicrobial resistance was low. In the other hand, majority of participants had positive attitude. Those participants who had positive attitude were significantly associated with antimicrobial resistance as compared to who had negative attitude.
\end{abstract}

Copyright $@ 2016$ Institute of Advanced Engineering and Science. All rights reserved.

\section{Corresponding Author:}

Desalegne Amare Zelellw,

Department of Nursing,

College of Medicine and Health Sciences,

Bahir Dar University,

Bahir Dar, Ethiopia.

Email: desa2001@yahoo.com, desalegnezelellw@gmail.com

\section{INTRODUCTION}

Antimicrobial resistance is a global concern [1]. Irrational use of medicines is a key reason for the increase and spread of antimicrobial resistance [2-5]. Several factors enhance irrational use of antibiotics, which could be doctors' knowledge and experience [6], diagnostic uncertainty, patients' expectations, lack of patient and health care professionals' education, pharmaceutical marketing, antibiotic selling without a prescription and economic [7].

Antimicrobial drug resistance is a fast mounting universal crisis. Many factors like inappropriate use of antibiotics, not following use of antibiotics by prescribing physician, unregulated sale of medicines and self-medication accredited to the advancement of resistance to several antimicrobials [8-9]. 
Lack or ignorance of microbiology services, using antibiotics for non bacterial infections like self remitted viral illness, have all led to overuse of antibiotics [10-11]. From the above factors, the selfmedication is the important one that further intensified by using leftover drugs from similar previous prescription or drugs obtained from known persons and easy accessibility of antimicrobial drugs at local pharmacy stores. The literature on self-medication with antimicrobial drugs in the developed world is limited. Several studies indicated that the use of household leftovers drugs, a pharmacy, or from other sources contribute for drug resistance [12-13].

Antibiotic resistance can be defined as the ability of a microorganism to survive and resist exposure to antimicrobial drugs, threatening the effectiveness of successful treatment of infection. Antibiotic resistance is a recognized public health issue at the local, national and global levels. Currently, antibiotic resistance is a concern as it is no longer a predictor of maintaining health within populations but an increasing threat to future of health as antibiotics are being misused [14-18]. The main aim of this study was to assess the level of knowledge and attitude of participants towards antimicrobial resistance.

\section{METHODS AND MATERIALS}

\subsection{Study Setting and Design}

The study was done at Debre Markos University from June to July 2015. It is $299 \mathrm{~km}$ far from the capital city of Ethiopia, Addis Ababa. All Debre Markos University extension students' who fulfill the inclusion criteria were the study population. Institutional based comparative cross-sectional survey was conducted.

\subsection{Inclusion and Excluded Criteria}

All non-health science and health science students who were registered in the university program as extension students were included in the study. Health science students were selected at least taking pharmacology course. Those students who dismissed, withdraw, and drop out were excluded from this study.

\subsection{Sample Size Determination and Sampling Technique}

The sample size was calculated using the assumption of $95 \%$ confidence interval, $80 \%$ power with one to one ratio of medical and non-medical students using the respective proportion of $72.5 \%$ and $61.5 \%$ from previous study [19]. Epi Info version 3.5.1 was used to calculate the required sample size using the following formula [20].

$$
\begin{aligned}
& n=\frac{\left[Z_{\alpha} \sqrt{(1+1 / m) \bar{p}(1-\bar{p})}+Z_{\beta} \sqrt{p_{0}\left(1-p_{0}\right) / m+p_{1}\left(1-p_{1}\right)}\right]^{2}}{\left(p_{0}-p_{1}\right)^{2}} \\
& \bar{p}=\frac{p_{1}+m p_{0}}{m+1}
\end{aligned}
$$

Including $10 \%$, none response rate the final sample was 670 . The list of students was taken from the university registrar and the sampling frame for medical and non-medical students were prepared from their list. Selection of participants carried out by applying simple random sampling method using random table. In order to get select participants, the learning classroom number was identified from each department.

\subsection{Data Collection Tools}

The data were collected using self-administered questionnaire. Four diploma and two-bachelor degree graduated nurses were data collectors and supervisors, respectively.

\subsection{Data Quality Control}

A pre-tested and standardized questionnaire was used. It was adapted and modified in to local context. Training was given for both data collectors and supervisors. Daily supervision was carried out during data collection period. Then, data cleaning was done using frequency, listing, sorting and to identify outliers and any missed values.

\subsection{Data Processing and Analysis}

Data clerk double entered the data into Epi data version 3.1 and transferred to SPSS version 21.0. The descriptive output of the study was presented on the tables. The association between dependent and independent variables was examined using binary and multiple logistic regressions. Those variables that had 
associations at binary stage with $\mathrm{p}$-value $<0.1$, not collinear and biologically important variables were entered in to multiple logistic regression models. The cut off point for association was p-value $<0.05$.

\subsection{Ethical Consideration}

Ethical approval and clearance was obtained from Debre Markos University, medicine and health science College research ethical review committee. A permission and support letter was written for each selected colleges and departments. Informed consent was obtained from each individuals and confidentiality was kept.

\section{RESULTS}

\subsection{Participants' Characteristics:}

Five hundred sixty one participants were participated in the study. Half of the $282(50.3 \%)$ of them were health science student. Majority $(63.3 \%)$ of participants were rural residence (Table 1 ).

Table 1. Socio Demographic Characteristic of Participants

\begin{tabular}{lcc}
\hline \multicolumn{1}{c}{ Variables } & Frequency (\%) \\
\hline Sex & Male & $336(60.2)$ \\
Residence & Female & $222(39.8)$ \\
Rural & & \\
Urban & $204(63.3)$ \\
Marital status & \\
Married & $83(14.9)$ \\
Not married & $475(85.1)$ \\
Occupation of Father & \\
employed & $77(14.7)$ \\
unemployed & $446(85.3)$ \\
Education of Father & \\
Illiterate & $386(72.0)$ \\
read or write and above & $150(28.0)$ \\
Occupation of mother & \\
employed & $57(10.4)$ \\
unemployed & $491(89.6)$ \\
Education of mother & $161(29.6)$ \\
Illiterate & $383(70.4)$ \\
Read/ write and above & \\
College $\quad$ Health science & $282(50.3)$ \\
Others & $279(49.7)$ \\
Year of education & $386(72.0)$ \\
$\quad \leq 2$ & $150(28.0)$ \\
\hline$>2$ &
\end{tabular}

\subsection{Participants' Behavior Towards the Use Antibiotics}

About $138(26.7 \%)$ of participants were used antibiotics longer than prescribed duration. Majority, $388(69.2 \%)$ of participants were checked the expiry date of the medicine before bought and used. Four hundred seventeen $(74.3 \%$ ) were consulted a physician before they bought their medicines. One hundred seventeen $(22.9 \%)$ of participants had never been completed the full course of their treatment (Table 2). 
Table 2. Participants' Behavior Towards Antibiotics Self-Medication

\begin{tabular}{|c|c|c|}
\hline Variables & Frequency & Percent \\
\hline \multicolumn{3}{|l|}{ Use of antibiotics longer than standard duration } \\
\hline Yes & 138 & 26.7 \\
\hline No & 287 & 55.6 \\
\hline \multicolumn{3}{|c|}{ Use of antibiotics shorter than standard duration } \\
\hline Yes & 148 & 32.8 \\
\hline No & 285 & 50.8 \\
\hline \multicolumn{3}{|c|}{ Use of antibiotics for self-limited non bacterial infections } \\
\hline Yes & 156 & 29.9 \\
\hline No & 158 & 49.5 \\
\hline \multicolumn{3}{|c|}{ Check the expiry date of the antibiotic before bought and used } \\
\hline Yes & 388 & 69.2 \\
\hline No & 122 & 21.7 \\
\hline \multicolumn{3}{|l|}{ consult a doctor before starting an antibiotic } \\
\hline Yes & 417 & 74.3 \\
\hline No & 93 & 16.6 \\
\hline \multicolumn{3}{|l|}{ Complete the full course of treatment } \\
\hline Never doing & 117 & 22.9 \\
\hline Always doing & 245 & 47.9 \\
\hline Sometimes doing & 107 & 20.9 \\
\hline Very occasional & 42 & 8.2 \\
\hline \multicolumn{3}{|c|}{ Give leftover antibiotics to your friend if she/he get sick } \\
\hline Never doing & 323 & 64.3 \\
\hline Always doing & 75 & 14.9 \\
\hline Sometimes doing & 72 & 14.3 \\
\hline Very occasional & 32 & 6.4 \\
\hline \multicolumn{3}{|l|}{ Discard the remaining, leftover medication } \\
\hline Never doing & 208 & 40.9 \\
\hline Always doing & 174 & 34.2 \\
\hline Sometimes doing & 85 & 16.7 \\
\hline Very occasional & 42 & 8.3 \\
\hline
\end{tabular}

\subsection{Knowledge and Attitude of Participants Towards Self-Medication}

Students who had less than or equal to 2 years of university educational status had inadequate knowledge than those who had more than 2 years of university educational status (Table 1).

About three quarter $399(72.3 \%)$ of participants ever had been treated by self-medication. The proportion of self-medication in the last 6 month was $116(29.3 \%)$. The median number of drugs prescribed in the last six month and one year was $2( \pm 2)$ and $2.5( \pm 3)$, respectively. Majority, $310(88.3 \%)$ of participants had self-medication for minor illness or minor fillings. Headache was $(50.6 \%)$ the commonest indicator for self-medication. Analgesics (47.7\%) commonly used self-prescribed medication compared to others. Twenty-one percent of participants always had been completed the full course of their treatment.

Rural students were 2.2 time practicing self-medication than the counter parts. Students who had positive attitude contribute to practice self-prescription and this leads to drug resistance. Knowledgeable students were $32 \%$ times less likely practicing self-medication (Table 3 ).

Only about $14.8 \%$ of study participants had adequate knowledge towards drug resistance as shown in Figure 4. Rural residences of the participants were significantly associated with drug resistance as compared to urban residence. Participants who had adequate knowledge were protective for self- medication and drug resistance as compare to those who had inadequate knowledge. Participants who had positive attitude had association with self-medication as compare to those who had negative attitude. 
Table 3. Knowledge and Attitude Towards Self-Medication at Debre Markos University

\begin{tabular}{|c|c|c|c|}
\hline \multirow{2}{*}{ Variables } & \multirow{2}{*}{ Frequency n (\%) } & \multicolumn{2}{|c|}{ OR } \\
\hline & & Crude & Adjusted \\
\hline \multicolumn{4}{|l|}{ Sex } \\
\hline Male & $336(60.2)$ & $1.262(0.778,2.049)$ & \\
\hline Female & $222(39.8)$ & 1 & \\
\hline \multicolumn{4}{|l|}{ Residence } \\
\hline Rural & $352(63.3)$ & $1.130(0.692,1.846)$ & \\
\hline Urban & 204(36.4) & 1 & \\
\hline \multicolumn{4}{|l|}{ Occupation of Father } \\
\hline employed & $77(14.7)$ & $0.651(0.300,1.417)$ & $1.941(0.690,5.459)$ \\
\hline unemployed & $446(85.3)$ & 1 & 1 \\
\hline \multicolumn{4}{|l|}{ Education of Father } \\
\hline Illiterate & $386(72.0)$ & $1.403(0.760,2.592)$ & \\
\hline read or write and above & $150(28.0)$ & 1 & \\
\hline \multicolumn{4}{|l|}{ Occupation of mother } \\
\hline employed & $57(10.4)$ & $0.887(0.360,2.186)$ & $1.156(0.361,3.694)$ \\
\hline unemployed & $491(89.6)$ & 1 & 1 \\
\hline \multicolumn{4}{|l|}{ Education of mother } \\
\hline Illiterate & $161(29.6)$ & $1.340(0.694,2.587)$ & \\
\hline read or write and above & $383(70.4)$ & 1 & \\
\hline \multicolumn{4}{|l|}{ College } \\
\hline Health science & $282(50.3)$ & $0.667(0.374,1.191)$ & $0.951(0.543,1.666)$ \\
\hline Others & $279(49.7)$ & 1 & 1 \\
\hline \multicolumn{4}{|l|}{ Year of education } \\
\hline$\leq 2$ & $386(72.0)$ & $1.745(0.950,3.207)$ & $0.296(0.125,0.701)$ \\
\hline$>2$ & $150(28.0)$ & 1 & 1 \\
\hline \multicolumn{4}{|l|}{ Knowledge of self-medication } \\
\hline Adequate Knowledgeable & $219(39.1)$ & $0.930(0.552,1.654)$ & \\
\hline Inadequate knowledgeable & $341(60.9)$ & 1 & \\
\hline \multicolumn{4}{|l|}{ Attitude towards self- medication } \\
\hline Positive attitude & 419(77) & $1.353(0.788,2.322)$ & \\
\hline negative attitude & $125(22.3)$ & 1 & \\
\hline
\end{tabular}

Table 4. Knowledge and Attitude of Students Towards Drug Resistance

\begin{tabular}{|c|c|c|c|}
\hline \multirow{2}{*}{ Variables } & \multirow{2}{*}{$\begin{array}{c}\text { Frequency } \\
\mathrm{n}(\%)\end{array}$} & \multicolumn{2}{|c|}{ OR } \\
\hline & & Crude & Adjusted \\
\hline \multicolumn{4}{|l|}{ Sex } \\
\hline Male & $336(60.2)$ & $0.654(0.353,1.212)$ & $0.590(0.301,1.155)$ \\
\hline Female & $222(39.8)$ & 1 & 1 \\
\hline \multicolumn{4}{|l|}{ Residence } \\
\hline Rural & $352(63.3)$ & $1.820(1.024,3.236)$ & $2.203(1.173,4.141)$ \\
\hline Urban & $204(36.4)$ & 1 & 1 \\
\hline \multicolumn{4}{|l|}{ College } \\
\hline Health science & $282(50.3)$ & $1.316(0.815,2.125)$ & $0.799(0.394,1.621)$ \\
\hline Others & $279(49.7)$ & 1 & 1 \\
\hline \multicolumn{4}{|l|}{ Year of education } \\
\hline$\leq 2$ & $386(72.0)$ & $1.745(0.950,3.207)$ & $1.657(0.795,3.454)$ \\
\hline$>2$ & $150(28.0)$ & 1 & 1 \\
\hline \multicolumn{4}{|l|}{ Attitude towards drug resistance } \\
\hline Positive attitude & $419(77)$ & $2.040(1.116,3.729)$ & $2.323(1.215,4.441)$ \\
\hline Negative attitude & $125(22.3)$ & 1 & 1 \\
\hline \multicolumn{4}{|l|}{ Knowledge of drug resistance } \\
\hline Adequate Knowledgeable & $79(14.8)$ & $0.354(0.186,0.675)$ & $0.320(0.158,0.647)$ \\
\hline Inadequate knowledgeable & $456(85.2)$ & 1 & 1 \\
\hline
\end{tabular}

\section{DISCUSSION}

The focus of this study was to assess the level of knowledge and attitude of participants towards antimicrobial resistance. This study revealed that only $14.8 \%$ of participants had adequate knowledge towards drug resistance. In line with this study conducted in Georgia showed that there was a lack of knowledge on proper antibiotic use and resistance [21-22].

Our study showed that $29.9 \%$ of participants used antibiotics for self-limited non-bacterial infections. Similarly, a report showed that more than $60 \%$ of participants believed that antibiotics were used for viral illnesses [23].

This study showed that $14.8 \%$ of participants knew about antimicrobial resistance. However, population based study in Sweden showed that $94 \%$ of the responders knew that bacteria could become resistant to antibiotics [24] and another study in Southern India showed that majority $88 \%$ of respondents 
were aware that if antibiotics had taken too often, they would not have been worked in the future [25]. Moreover, a study conducted in Ethiopia on nurses and physicians, $72.2 \%$ of them knew about antimicrobial resistance [26]. The difference might be due to variation in sample size, age and educational status.

Our study showed that $22.3 \%$ of participants believed that inappropriate use of antimicrobials agents could cause drug resistance. This is lower than the study conducted in Sweden that the majority of respondents had an appropriate and restrictive attitude towards antibiotics [24]. This may be due to the difference in socio-demographic characteristics of respondents. Other study explore that the erosion of effective antimicrobials continues as they witness the increased frequency of resistance to all drugs [27]. In addition, study revealed that respondents had little understanding of the concept of antibiotic resistance but they thought that over-using antibiotics was unwise because it would reduce their future effectiveness [28]. Another study conducted in the united state of America showed that $27 \%$ believed that taking antibiotics when they had a cold made them better more quickly, $32 \%$ believed that taking antibiotics when they had a cold prevented more serious illness, and $48 \%$ expected a prescription for antibiotics when they were ill enough from a cold to seek medical attention. These misguided beliefs and expectations were associated with a lack of awareness of the dangers of antibiotic use [29].

This study showed that only $20.9 \%$ of students were always complete the full course of the given treatment. No significant difference was observed between medical (29.0\%) and non-medical students $(27.1 \%)$ in terms of self- medication and the purchase of antibiotics without a prescription [19], [30]. Study conducted in Saudi, $75 \%$ of students have heard about the resistance of bacteria. However, more than $79 \%$ of students did not think that recurrence antibiotic use could decrease the effectiveness of the drug [31].

In this study, participants believed that self-medication could cause bacteria resistance. In consistent, other reports showed that self-medication could cause to such antibiotics resistance and may precipitate the emergence of multiple-resistant organisms that would be difficult to treat and this has caused increased morbidity [32-35]. Many reports outlined the direct relation between the abuse of antibiotics and increased bacterial resistance [36-38]. The misuse of antibiotics is another reason for the development of bacterial resistance [39].

\section{CONCLUSION}

The overall knowledge of participants regarding to antimicrobial resistance was inadequate. In the other hand, majority of participants had positive attitude. Those participants who had positive attitude were significantly associated with antimicrobial resistance as compared to who had negative attitude. Rural residences of the participants were significantly associated with drug resistance as compared to urban residence. Participants who had adequate knowledge were protective for self-medication and drug resistance as compare to those who had inadequate knowledge.

\section{COMPETING INTEREST}

All authors have confirmed that they have no competing interest. We have no received reimbursements, fees, funding, or salary, share, gain or lose from an organization that may in any way gain or lose financially from the publication of this manuscript, either in the past five, now or in the future. In addition, there is no financial and non-financial competing interest in relation to this paper. Currently, any content of this manuscript do not applying for any patents. Informed consent was obtained from each participant to participate in this study and the informed consent obtained from each subject for publication.

\section{ACKNOWLEDGEMENT}

We are grateful thanks to Debre Markos University for technical and financial support. Our deepest gratitude goes to thanks for the data collectors and study participants.

\section{REFERENCES}

[1] D. M. Shlaes, et al., "SHEA position paper: Society for healthcare epidemiology of America and infectious diseases society of America joint committee on the prevention of antimicrobial resistance: Guidelines for the prevention of antimicrobial resistance in hospitals," Infect. Control Hosp. Epidemiol, vol. 18, pp. 275-91, 1997.

[2] I. C. Gyssens, "Quality measures of antimicrobial drug use," Int. J. Antimicrob. Agents, vol. 17, pp. 9-19, 2001.

[3] P. Nordberg, et al., "Antibacterial Drug Resistance. Background document Priority Medicines for Europe and the World. A Public Health Approach to Innovation," WHO, Geneva, 2004.

[4] A. Srinivasan, et al., "A survey of knowledge, attitudes, and beliefs of house staff physicians from various specialties concerning antimicrobial use and resistance," Arch. Int. Med, vol. 164, pp. 1451-1456, 2004. 
[5] D. J. Morgan, et al., "Non-prescription antimicrobial use worldwide: a systematic review," Lancet Infect Dis, vol. 11, pp. 692-701, 2011.

[6] S. Cetinkaya, et al., "Knowledge and behavior of the pediatricians on rational use of antibiotics," Afr. J. Pharm. Pharacol, vol. 4, pp. 783-79, 2010.

[7] Orton P., "Pressure to prescribe," in Souls by Swaffham PWR, "Antimicrobial Resistance," pp. 139-143, 2001.

[8] R. T. Varghese and R. Das, "Antimicrobial drug resistance in India, Possible causes," Asian Stud Med, vol. 1, pp. 151-54, 2010.

[9] N. A. Aleykutty, et al., "Effect of regulations on the appropriate use of antibiotics," Int J Pharma Bio Sci, vol. 2, pp. 32-35, 2011.

[10] Global Antibiotic Resistance Partnership-India (GARP-India), "Situation analysis-Antibiotic Use and Resistance in India," Global Antibiotic Resistance Partnership-India National Working Group, pp. 9-12, 2011-2013.

[11] J. K. Thomas, et al., "Pharmacodynamic evaluation of factors associated with the development of bacterial resistance in acutely ill patients during therapy," Antimicrob Agents Chemother, vol. 42, pp. 521, 1998.

[12] P. B. Richman, et al., "Oral antibiotic use without consulting a physician: a survey of ED patients," Am J Emerg Med, vol. 19, pp. 57-60, 2001.

[13] E. J. Vanden, et al., "Consumer attitudes and use of antimicrobial drugs," Emerg Infect Dis, vol. 9, pp. 1128-35, 2003.

[14] World Health Organization (WHO), "The antimicrobial resistance: global report on surveillance," 2014. http://www.who.int/drugresistance/documents/surveillancereport/en/.

[15] World Health Organization (WHO), "The evolving threat of antimicrobial resistance options for action," 2012. http://www.who.int/patientsafety/ implementation/amr/publication/en/. ERSS ISBN-Number: 90-6960-131-1.

[16] "The European antimicrobial resistance surveillance system (EARSS) annual report," 2004. http://www.ecdc.europa.eu/en/activities/surveillance/EARSNet/Documents/2004_EARSS_Annual_Report.

[17] World Health Organization (WHO), "Antibiotic resistance," http://www. euro.who.int/en/what-we-do/healthtopics/disease-prevention/antibiotic-resistance.

[18] P. Nordberg, et al., "Antibacterial resistance. Background document for the WHO project: priority medicines for Europe and the World - a public health approach to innovation," Geneva, WHO, 2004.

[19] A. R. Ghadeer, et al., "A cross-sectional study on knowledge, attitude and behavior related to antibiotic use and resistance among medical and non-medical university students in Jordan," African Journal of Pharmacy and Pharmacology, vol/issue: 6(10), pp. 763-770, 2012.

[20] V. Kasiulevičius, et al., "Sample size calculation in epidemiological studies," Gerontologija, vol/issue: 7(4), pp. 225-231, 2006.

[21] K. Ketevan, et al., "Antibiotic use and resistance: a cross-sectional study exploring knowledge and attitudes among school and institution personnel in Tbilisi, Republic of Georgia," BMC Res Notes, vol. 8, pp. 495, 2015.

[22] "Validation of the parental knowledge and attitude towards antibiotic usage and resistance among children in Tetovo, the Republic of Macedonia Edita ALILI-IDRIZI, Merita DAUTI, Ledjan MALAJ," 2014.

[23] M. M. Azevedo, et al., "Portuguese students' knowledge of antibiotics: a cross-sectional study of secondary school and university students in Braga," BMC Public Health, vol. 9, pp. 359, 2009.

[24] M. Vallin, et al., "Knowledge and Attitudes towards Antibiotic Use and Resistance - A Latent Class Analysis of a Swedish Population-Based Sample," PLoS ONE, vol/issue: 11(4), 2016.

[25] A. K. A. Khan, et al., "Antibiotic Resistance and Usage- A Survey on the Knowledge, Attitude, Perceptions and Practices among the Medical Students of a Southern Indian Teaching Hospital," Journal of Clinical and Diagnostic Research, vol/issue: 7(8), pp. 1613-1616, 2013.

[26] A. Bayeh, et al., "Knowledge and beliefs on antimicrobial resistance among physicians and nurses in hospitals in Amhara Region, Ethiopia," BMC Pharmacology and Toxicology, vol. 15, pp. 26, 2015. http://www.biomedcentral.com/2050-6511/15/26.

[27] B. L. Stuart and M. Bonnie, "Antibacterial resistance worldwide: causes, challenges and responses," Nature medicine supplement, vol/issue: 10(12), 2004. http://www.nature.com/naturemedicine.

[28] N. Pauline, et al., "Public Beliefs about Antibiotics, Infection and Resistance: A Qualitative Study," Antibiotics, vol. 2, pp. 465-476, 2013. www.mdpi.com/journal/antibiotics.

[29] V. E. Jodi, et al., "Consumer Attitudes and Use of Antibiotics Emerging Infectious Diseases," vol/issue: 9(9), 2003.

[30] H. James, et al., "Evaluation of the knowledge, attitude and practice of self-medication among first-year medical students," Med. Princ. Pract, vol. 15, pp. 270-275, 2006.

[31] A. B. Njood, et al., "The assessment of knowledge, attitude and practice of antibiotics usage among saudi female students in princess nourah university," International Journal of Health and Life Sciences, vol/issue: 2(1), pp. 2440, 2016.

[32] World Health Organization, "Global Strategy for Containment of Antimicrobal Resistance: World Health Organization," Communicable Diseases Surveillance and Response, (CRS), 2001. WHO/CDS/CRS/DRS/2001.2.2001.

[33] J. O. Fadara and I. Tamuno, "Antibiotic Self-medication among university medical undergraduates in Northern Nigeria," J. Pub Health Epidemiol, vol/issue: 3(5), pp. 217-220, 2011.

[34] N. Aswapokee, et al., "Pattern of antibiotic use in medical wards of a university hospital, Bankok, Thailand," Rev Infect Dis, vol/issue: 12(1), pp. 136-141, 1990.

[35] N. I. Okeke, et al., "Socio-economic and Behavioral Factors Leading to Acquired Bacterial Resistance to Antibiotics in Developing Countries," Emerg Infect Dis, vol/issue: 5(1), pp. 18-27, 1999. 
[36] H. Bauchner, et al., "Parents, physicians, and antibiotic use," Pediatrics, vol. 103, pp. 395-401, 1999.

[37] S. L. Bronzwaer, et al., "A European study on the relationship between antimicrobial use and antimicrobial resistance," Emerg Infect Dis, vol. 8, pp. 278-82, 2002.

[38] H. Seppala, et al., "The effect of changes in the con-sumption of macrolide antibiotics on erythromycin resistance in group a streptococci in Finland. Finnish Study Group for Antimicrobial Resistance," N Engl J Med, vol. 337, pp. 441-6, 1997.

[39] D. J. Austin, et al., "The relationship between the volume of antimicrobial consumption in human communities and the frequency of resistance," Proc Natl Acad Sci USA, vol. 96, pp. 1152-6, 1999. 